\section{Avaliação da alimentação complementar nos dois primeiros anos de vida: proposta de indicadores e de instrumento}

\author{
Assessing complementary feeding practices in the \\ first two years of life: a proposal for indicators \\ and a monitoring tool
}

\section{Evaluación de la alimentación suplementaria en los dos primeros años de vida: propuesta de indicadores e instrumentos}

\author{
1 Universidade do Estado do \\ Rio de Janeiro, Rio de Janeiro, \\ Brasil. \\ 2 Instituto de Saúde, \\ Secretaria de Estado da \\ Saúde de São Paulo, São \\ Paulo, Brasil. \\ Correspondência \\ J. M. Oliveira \\ Universidade do Estado do \\ Rio de Janeiro. \\ Rua São Francisco Xavier \\ 524,12 o andar, sala $12.007 \mathrm{D}$ \\ Rio de Janeiro, $R J$ \\ 20755-330, Brasil. \\ jmonutri@yahoo.com.br
}

\begin{abstract}
The aim of this article is to propose indicators and a tool for monitoring complementary feeding in under-two children in Brazil, describing its formulation. The study constructed a theoretical model of attributes, components, and markers of complementary feeding that serves as the basis for systematizing the feeding recommendations related to key concepts in the model. The recommendations were transformed into indicators. A questionnaire was constructed, based on the indicators' variables. Two workshops were held with specialists in complementary feeding to discuss the indicators and the instrument, in addition to four pretests with the target population. The study presents 18 indicators related to the timing, nutritional adequacy, and safety of complementary feeding, as well as a questionnaire that allows the construction of the proposed indicators. The model can be applied in surveys with face-to-face or telephone interviews or in activities in health services to monitor food consumption. Further research is necessary to validate the questionnaire.
\end{abstract}

Supplementary Feeding; Infant Nutrition; Recommended Dietary Allowances
Juliana Martins Oliveira 1 Inês Rugani Ribeiro de Castro 1

Gabriela Bioni e Silva 1

Sonia Isoyama Venancio 2

Sílvia Regina Dias Médici Saldiva ${ }^{2}$

\section{Resumo}

O objetivo deste artigo é apresentar indicadores e instrumento para monitoramento da alimentação complementar entre crianças menores de dois anos no Brasil, descrevendo seu processo de formulação. Com base em um modelo teórico sobre atributos, componentes e marcadores de alimentação complementar construído neste estudo, foram sistematizadas as recomendações alimentares referentes a conceitos-chave desse modelo. Essas recomendações foram transformadas em indicadores. Um questionário foi construído com base nas variáveis desses indicadores. Foram realizadas duas oficinas com especialistas em alimentação complementar para discussão sobre os indicadores e o instrumento e quatro pré-testes com a população de interesse. São apresentados 18 indicadores referentes à oportunidade, à adequação nutricional e à segurança da alimentação complementar, e um questionário que permite a construção dos indicadores propostos. Ele pode ser aplicado em inquéritos com entrevistas face a face, por telefone ou em atividades de monitoramento do consumo alimentar em serviços de saúde. São necessárias pesquisas ulteriores para a validação deste questionário.

Alimentação Complementar; Nutrição do Lactente; Recomendações Nutricionais 


\section{Introdução}

A promoção da alimentação complementar saudável vem se tornando uma prioridade na agenda das políticas públicas de alimentação e saúde. No Brasil, ações nesse sentido foram iniciadas no começo dos anos 2000 1, sendo a mais recente a Estratégia Amamenta e Alimenta Brasil, que tem por objetivo promover a prática da amamentação e da alimentação complementar saudável na Atenção Básica ${ }^{2}$. Nesse contexto de priorização do tema no âmbito das políticas públicas, o monitoramento de indicadores referentes às práticas alimentares do início da vida é fundamental, pois pode subsidiar o desenvolvimento, a avaliação e o redirecionamento de tais políticas ${ }^{3}$. Esse monitoramento tem sido realizado por meio de diferentes estratégias que se complementam no âmbito do Sistema de Vigilância Alimentar e Nutricional (SISVAN), quais sejam: o sistema de informação do Sistema Único de Saúde (SUS) alimentado pelos profissionais da rede básica de saúde e que abarca dados de estado nutricional e de consumo alimentar dos usuários do SUS 4; os inquéritos populacionais de base domiciliar, como a Pesquisa Nacional de Demografia e Saúde (PNDS) 5 e os inquéritos populacionais mais simples e de custo mais baixo do que os de base domiciliar, como os realizados durante a Campanha Nacional de Imunização 6 .

Inquéritos neste último formato têm sido realizados em municípios brasileiros desde 19957 com o propósito de monitoramento da amamentação. Nos anos de 1999 e 2008, eles foram realizados nas capitais brasileiras pelo Ministério da Saúde com o apoio de Secretarias Estaduais e Municipais de Saúde 8,9. Ainda que esses inquéritos incluam alguns indicadores de alimentação complementar, não abarcam todos os aspectos de interesse sobre essa prática alimentar.

No cenário internacional, a Organização Mundial da Saúde (OMS) lançou, a partir de 1991, publicações sobre monitoramento da amamentação 10 e, a partir de 1998, sobre alimentação complementar 11 . A mais atual consiste num conjunto de três materiais sobre o monitoramento de práticas alimentares de crianças até dois anos de idade: o primeiro apresenta um elenco de indicadores sobre amamentação e alimentação complementar 12; o segundo, um instrumento para a coleta de dados para estudos de base domiciliar que permite a construção desses indicadores 13; e o terceiro, a descrição da situação de alguns indicadores de alimentação complementar em vários países com base em resultados de pesquisas de demografia e saúde 14 .

Entretanto, o conjunto de indicadores propostos pela OMS não abrange todo o leque de práticas alimentares que se consideram relevantes monitorar no contexto brasileiro, como o consumo de produtos ultraprocessados 15. Dados da II Pesquisa de Prevalência de Aleitamento Materno nas Capitais Brasileiras e Distrito Federal 8 indicam, por exemplo, consumo expressivo de bolachas e salgadinhos $(71,7 \%)$ e de refrigerantes $(11,6 \%)$ entre crianças com idade entre 9 e 11,9 meses. Além disso, alguns dos indicadores propostos apresentam fragilidades em sua construção, seja nos componentes levados em conta para o seu cálculo, seja na estrutura da pergunta utilizada no instrumento de coleta de dados. Outra limitação é o fato de, por ser bastante extenso, tal questionário não se adequar a estudos que demandem um tempo mais curto para coleta de dados, como, por exemplo, aqueles realizados em dia de campanhas de vacinação ou em atividades de monitoramento do consumo alimentar na rotina dos serviços de saúde.

Com o intuito de melhorar a qualidade do monitoramento das práticas de alimentação complementar no Brasil, neste momento de consolidação das políticas de promoção da alimentação complementar saudável, este artigo tem o propósito de descrever o processo de formulação de um conjunto de indicadores para monitoramento da alimentação complementar entre crianças brasileiras menores de dois anos e de um instrumento para coleta de dados que permita a construção de tais indicadores.

\section{Métodos}

O estudo, de caráter metodológico, tomou por base o percurso proposto por Reichenheim \& Moraes 16 para o desenvolvimento de instrumentos de aferição. Primeiramente, foi construído um modelo teórico; em seguida, os conceitoschave desse modelo foram desdobrados em medidas empíricas (indicadores) e, por fim, foi construído um instrumento para a coleta de dados que possibilitasse a obtenção dos indicadores de interesse.

\section{Modelo teórico}

O modelo teórico (Figura 1) busca sistematizar os principais atributos, componentes e marcadores da alimentação complementar. Ele foi construído com base em revisão bibliográfica sobre práticas de alimentação complementar preconizadas na Estratégia Nacional Para Alimentação Complementar Saudável 17, indicadores de alimentação complementar recomendados pela OMS 12 e estudos que se basearam em diferentes instrumentos para a construção 
de indicadores de alimentação complemen$\operatorname{tar} 7,18,19,20,21$.

Os três atributos da alimentação complementar aqui sistematizados são: oportunidade, adequação nutricional e segurança. A oportunidade diz respeito à idade de introdução da alimentação complementar, sendo definida como precoce quando iniciada antes dos seis meses, oportuna se iniciada entre seis e sete meses e tardia quando iniciada a partir dos sete meses de idade da criança.

A adequação nutricional se expressa por meio de quatro componentes: presença, na alimentação, de nutrientes específicos necessários ao pleno crescimento e desenvolvimento infantil (por exemplo, ferro e vitamina A); variedade dos alimentos oferecidos; densidade energética dos alimentos e preparações e ausência de produtos ultraprocessados na alimentação. A variedade é caracterizada pela quantidade de grupos de alimentos presentes na alimentação da criança, a saber: cereais ou tubérculos, hortaliças, carnes ou ovos, leguminosas, frutas e leite. A densidade energética é definida como quantidade de energia fornecida por peso de alimento ${ }^{1}$. Foram tomados como marcadores da densidade ener- gética da alimentação a consistência das preparações, a frequência de refeições com preparações ofertadas na consistência adequada para a idade da criança e a quantidade oferecida dessas preparações em cada refeição. Por fim, a ausência de produtos ultraprocessados na alimentação é assumida como um componente da adequação nutricional da alimentação complementar. A presença desses produtos caracteriza uma prática inadequada, devido à alta concentração de açúcar e gordura em pequenas porções do alimento - o que representa elevada densidade energética - e de sódio e, muitas vezes, baixos teores de micronutrientes 1,22 .

A segurança abarca dois componentes: a inocuidade das preparações e a ausência de aditivos na alimentação. O uso de água própria para consumo humano para higiene e preparo das refeições, assim como a limpeza de utensílios como mamadeiras e/ou copos com bicos, são fatores cruciais para o alcance da inocuidade da alimentação 23. Por outro lado, quando se evita o consumo de alimentos ricos em aditivos, como corantes artificiais, diminui-se o risco de a criança desenvolver hipersensibilidade alimentar 24,25. Tomamos como marcador da presença

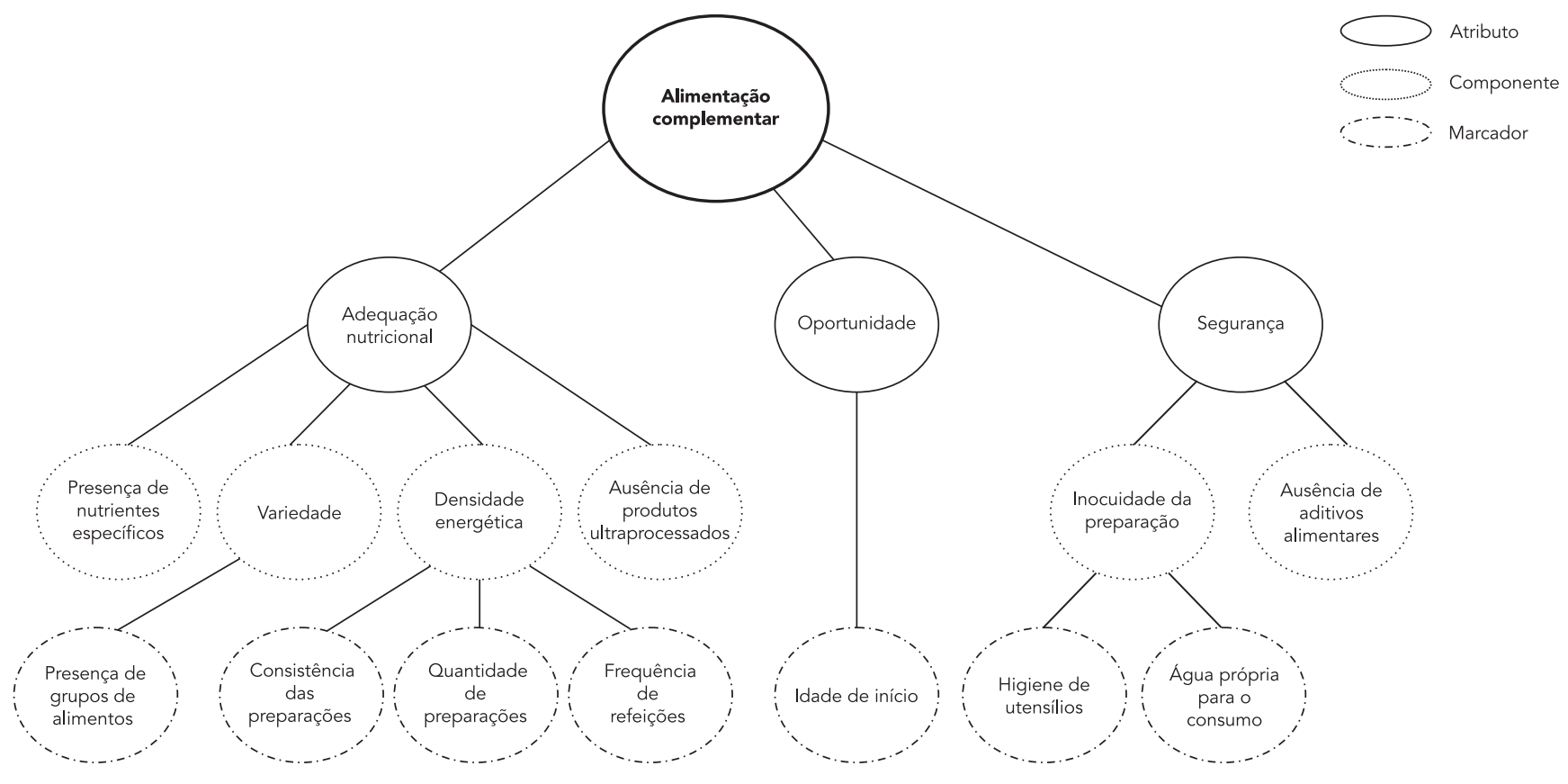


de aditivos na alimentação o consumo de produtos ultraprocessados.

\section{Construção dos indicadores}

Tendo por base o modelo teórico, foram definidas as variáveis e os indicadores que expressam, no nível empírico, os conceitos que o compuseram. Para isso, foram sistematizadas as recomendações nacionais e internacionais $1,17,26,27$ referentes aos atributos, componentes e marcadores da alimentação complementar propostos no modelo teórico. Para cada item do modelo foi definida apenas uma recomendação, sendo algumas delas adotadas sem modificação em relação às referências consultadas e outras, reescritas. A Tabela 1 sistematiza as recomendações das referências consultadas e apresenta aquela que foi adotada neste estudo. Em seguida, foi elaborada uma matriz de transformação dos conceitoschave 16,28 do modelo teórico e das recomendações adotadas em indicadores e respectivas fórmulas para sua construção. Essa matriz está apresentada na Tabela 2. Os indicadores propostos pela OMS 12 foram incorporados, adaptados, reformulados ou complementados em função de sua adequação aos conceitos-chave do modelo e às recomendações adotadas na matriz.

\section{Construção do instrumento para coleta de dados (questionário)}

O instrumento para coleta de dados foi baseado no questionário da II Pesquisa Nacional Sobre Práticas Alimentares no Primeiro Ano de Vida 8 , no questionário proposto pela OMS para a investigação de Práticas Alimentares Infantis 13 e no elenco de indicadores criados. Foi construída uma matriz em que foram cotejadas todas as perguntas referentes a práticas alimentares existentes nos dois questionários. Em seguida, com base no questionário usado na II Pesquisa Nacional, foram identificadas as perguntas que precisavam ser inseridas ou modificadas para a construção dos indicadores criados. O questionário da OMS foi então consultado e as perguntas que correspondiam àquelas que precisavam ser inseridas ou modificadas eram aproveitadas. As perguntas a serem incluídas ou modificadas e que não eram encontradas no instrumento da OMS foram produzidas pelos pesquisadores. Concluídos esses procedimentos, chegou-se a uma primeira versão do instrumento de aferição proposto pelo estudo.

Essa versão foi submetida à apreciação em uma oficina com 12 especialistas em alimentação complementar de diferentes instituições, dentre as quais pesquisadoras, professoras e ges- toras da Atenção Básica, que ocorreu na Universidade do Estado do Rio de Janeiro, com duração de dois turnos. Examinaram-se o modelo teórico, os indicadores e foi gerada uma segunda versão do questionário.

Foram realizados quatro pré-testes do questionário com mães de crianças menores de dois anos em unidades de saúde do Rio de Janeiro. Três deles foram dedicados a averiguar o entendimento das mães em relação às perguntas e um deles teve o objetivo de testar operacionalmente o instrumento. Os pré-testes de entendimento foram realizados na Policlínica Piquet Carneiro, na cidade do Rio de Janeiro. No primeiro, perguntou-se a 11 mães o que elas entendiam por mingau, comida de sal, miúdos/vísceras, legumes/verduras, suco industrializado e macarrão instantâneo.

Com base nesse pré-teste, foi gerada uma terceira versão do questionário, utilizada no préteste de operacionalização, realizado em três Unidades Básicas de Saúde distribuídas em diferentes regiões da cidade do Rio de Janeiro (Zona Norte, Zona Sul e Zona Oeste), no dia da segunda etapa da Campanha Nacional de Vacinação de 2012. Das 100 mães de crianças menores de um ano convidadas a participar de uma amostra de conveniência, 99 concordaram e responderam ao questionário. Nessa ocasião o objetivo central foi testar, em uma escala maior, a viabilidade operacional e o tempo de aplicação do questionário, incluindo o bloco habitual de questões sobre o nascimento da criança e sobre dados sociodemográficos da mãe. Em caráter complementar, objetivou-se conhecer a frequência de algumas práticas alimentares. Os resultados foram analisados em frequências simples e subsidiaram a discussão ocorrida na oficina de especialistas realizada em São Paulo, na qual os indicadores e o instrumento contemplados no presente estudo foram utilizados como um dos materiais de apoio. Nesse encontro, organizado pelo Instituto de Saúde de São Paulo em parceria com a Coordenação de Saúde da Criança e Aleitamento Materno e com a Coordenação-Geral de Alimentação e Nutrição, ambas do Ministério da Saúde, o objetivo era a construção do instrumento de coleta de dados que será utilizado na próxima pesquisa sobre práticas de alimentação infantil nas capitais brasileiras e Distrito Federal. Um dos produtos dessa oficina foi a quarta versão do questionário, o que gerou a necessidade dos outros dois pré-testes de entendimento.

No segundo pré-teste de entendimento das mães, foram entrevistadas 13 pessoas e o enfoque foi direcionado para alimento sólido, semissólido e pastoso, fritura, verduras de folhas, hambúrguer, achocolatado e alimento adoçado. No 
Cotejamento das recomendações da Organização Mundial da Saúde (OMS), Ministério da Saúde e Secretaria Municipal de Saúde e Defesa Civil do Rio de Janeiro (SMSDC-RJ) e recomendações adotadas neste estudo.

\begin{tabular}{|c|c|c|c|c|}
\hline \multirow{2}{*}{$\begin{array}{l}\text { Atributos/ } \\
\text { Componentes/ } \\
\text { Marcadores }\end{array}$} & \multirow[b]{2}{*}{ OMS $(2003 *)$} & \multicolumn{2}{|c|}{ Recomendações } & \multirow[b]{2}{*}{ Adotada no estudo } \\
\hline & & $\begin{array}{l}\text { Ministério da Saúde } \\
(2002 * * / 2010 * * *)\end{array}$ & SMSDC-RJ (2012 \#) & \\
\hline Oportunidade & $\begin{array}{l}\text { Praticar amamentação exclusiva } \\
\text { desde o nascimento até os } 6 \\
\text { meses de idade e introduzir } \\
\text { alimentos complementares aos } \\
6 \text { meses (180 dias) enquanto } \\
\text { continua a amamentação. }\end{array}$ & $\begin{array}{l}\text { Passo 1: Dar somente leite } \\
\text { materno até os } 6 \text { meses, } \\
\text { sem oferecer água, chás ou } \\
\text { qualquer outro alimento. } \\
\text { Passo 2: A partir dos } 6 \\
\text { meses, introduzir, de forma } \\
\text { lenta e gradual, outros } \\
\text { alimentos, mantendo o } \\
\text { leite materno até } 2 \text { anos de } \\
\text { idade ou mais. }\end{array}$ & $\begin{array}{l}\text { Passo 1: Dar somente leite } \\
\text { materno até os } 6 \text { meses, } \\
\text { sem oferecer água, chás ou } \\
\text { qualquer outro alimento. } \\
\text { Introduzir alimentos } \\
\text { complementares a partir do } \\
\text { 6o mês de vida da criança. }\end{array}$ & $\begin{array}{c}\text { Iniciar a alimentação } \\
\text { complementar, incluindo a } \\
\text { água, aos } 6 \text { meses de idade. }\end{array}$ \\
\hline \multicolumn{5}{|c|}{ Adequação nutricional } \\
\hline Variedade & $\begin{array}{l}\text { Alimente com a maior variedade } \\
\text { de alimentos para assegurar que } \\
\text { a necessidade de nutrientes foi } \\
\text { alcançada. Carne, aves, peixes } \\
\text { ou ovo deveriam ser oferecidos } \\
\text { sempre que possível. Dietas } \\
\text { vegetarianas podem não alcançar } \\
\text { a necessidade de nutrientes } \\
\text { para essa idade, a menos que se } \\
\text { usem suplementos ou alimentos } \\
\text { fortificados. }\end{array}$ & $\begin{array}{l}\text { Passo 6: Oferecer à criança } \\
\text { diferentes alimentos ao dia. } \\
\text { Uma alimentação variada é } \\
\text { uma alimentação colorida. } \\
\text { Passo 7: Estimular o } \\
\text { consumo diário de frutas, } \\
\text { verduras e legumes } \\
\text { nas refeições. } \\
\text { Introduzir carnes a partir do } \\
\text { sexto mês. O ovo já pode } \\
\text { ser introduzido inteiro } \\
\text { (clara e gema). }\end{array}$ & $\begin{array}{c}\text { As refeições (almoço e } \\
\text { jantar) devem conter um } \\
\text { alimento de cada grupo } \\
\text { (cereais ou tubérculos + } \\
\text { legumes + verduras + } \\
\text { carnes + leguminosas). } \\
\text { Introduzir carnes a partir do } \\
\text { 6o mês. } \\
\text { O ovo já pode ser } \\
\text { introduzido inteiro } \\
\text { (clara e gema). }\end{array}$ & $\begin{array}{c}\text { As refeições (almoço e jantar) } \\
\text { devem conter um alimento } \\
\text { de cada grupo (cereais ou } \\
\text { tubérculos + legumes + } \\
\text { verduras + carnes ou ovo + } \\
\text { leguminosas). }\end{array}$ \\
\hline \multicolumn{5}{|c|}{ Densidade energética } \\
\hline Quantidade & $\begin{array}{c}\text { Comece aos } 6 \text { meses de idade } \\
\text { com pequenas quantidades de } \\
\text { comida e aumente conforme } \\
\text { a criança vai ficando mais } \\
\text { velha, enquanto mantém a } \\
\text { amamentação. A quantidade de } \\
\text { energia advinda dos alimentos } \\
\text { complementares para crianças } \\
\text { amamentadas em países em } \\
\text { desenvolvimento deve ser de } \\
\text { aproximadamente } 200 \text { kcal/dia } \\
\text { para 6-8 meses, 300kcal para } \\
\text { 9-11 meses e 550kcal para 12-13 } \\
\text { meses. Em países industrializados } \\
\text { essa estimativa difere por causa } \\
\text { das diferenças de ingestão média } \\
\text { de leite materno (130, } 310 \text { e } 580 \\
\text { kcal/dia para 6-8, 9-11 e 12-23 } \\
\text { meses, respectivamente). }\end{array}$ & $\begin{array}{c}\text { A partir de } 6 \text { meses: Iniciar } \\
\text { com } 2 \text { a } 3 \text { colheres de sopa } \\
\text { por refeição e aumentar } \\
\text { a quantidade conforme } \\
\text { aceitação. } \\
\text { A partir dos } 7 \text { meses: } 2 / 3 \\
\text { de uma xícara ou tigela de } \\
250 \text { mL por refeição. } \\
\text { De } 9 \text { a } 11 \text { meses: } 3 / 4 \text { de } \\
\text { uma xícara ou tigela de } \\
250 \text { mL por refeição. } \\
\text { De } 12 \text { a } 24 \text { meses: } 1 \text { xícara } \\
\text { ou tigela de } 250 m L \text { por } \\
\text { refeição. }\end{array}$ & $\begin{array}{c}6 \text { meses: } 2 \text { a } 3 \text { colheres de } \\
\text { sopa por refeição. } \\
7 \text { meses: } 4 \text { a } 5 \text { colheres de } \\
\text { sopa por refeição. } \\
8 \text { a } 11 \text { meses: } 6 \text { a } 7 \text { colheres } \\
\text { de sopa por refeição. } \\
12 \text { a } 24 \text { meses: } 8 \text { a } 10 \\
\text { colheres de sopa por } \\
\text { refeição. }\end{array}$ & $\begin{array}{c}6 \text { meses: } 2 \text { a } 3 \text { colheres sopa } \\
\text { por refeição. } \\
7 \text { meses: } 4 \text { a } 5 \text { colheres de } \\
\text { sopa por refeição. } \\
8 \text { a } 11 \text { meses: } 6 \text { a } 7 \text { colheres } \\
\text { de sopa por refeição. } \\
12 \text { a } 24 \text { meses: } 8 \text { a } 10 \\
\text { colheres de sopa por } \\
\text { refeição. }\end{array}$ \\
\hline
\end{tabular}

(continua) 
Tabela 1 (continuação)

\begin{tabular}{lcc}
\hline Atributos/ & \multicolumn{2}{c}{ Recomendações } \\
Componentes/ & Ministério da Saúde $(2003 *)$ & $(2002 * * / 2010 * \star \star)$
\end{tabular}

Densidade energética

Frequência

Consistência

Oferta de alimentos fonte de nutrientes específicos
Para os bebês amamentados saudáveis, refeições de alimentos complementares devem ser fornecidas 2-3 vezes por dia aos 6

a 8 meses de idade e 3-4 vezes por dia para 9 a 24 meses de idade, com lanches saudáveis adicionais (como um pedaço de fruta ou pão) oferecidos 1-2 vezes por dia, conforme desejado. Lanches são definidos como alimentos consumidos entre as refeições, que geralmente a criança come sozinha, e fáceis de preparar.

Se a densidade energética ou a quantidade de comida por refeição for baixa, pode ser necessário aumentar a frequência das refeições.

As crianças podem comer alimentos na forma de purê, amassados e/ ou semissólidos a partir dos 6 meses. Aos 12 meses, a maioria das crianças pode comer os mesmos tipos de alimentos consumidos pela família (mantendo em mente a necessidade de alimentos ricos em nutrientes). Evitar alimentos que podem causar asfixia (ou seja, itens que têm uma forma e/ou consistência que pode levá-los a se alojar na traquéia, como nozes, uvas, cenoura crua).

Frutas ricas em vitamina $A$ e hortaliças devem ser comidas diariamente.

Carne, aves, peixes ou ovo devem ser oferecidos sempre que possível.
Passo 3: Após 6 meses, dar alimentos complementares (cereais, tubérculos, carnes, leguminosas, frutas e legumes) 3 vezes ao dia, se a criança estiver em aleitamento materno.

Passo 5: A alimentação complementar deve ser espessa desde o início e oferecida de colher. Iniciar com a consistência pastosa (papas/purês) e, gradativamente, aumentar a consistência até chegar à alimentação da família.

Passo 6: Oferecer à criança diferentes alimentos ao dia. Uma alimentação variada é uma alimentação colorida.

Passo 7: Estimular o consumo diário de frutas, legumes e verduras nas refeições.

\section{Oferecer à criança} amamentada 3 refeições/dia (2 papas de fruta e almoço) no 6o mês e 4 refeições a partir do 7o mês (2 papas de fruta, almoço e jantar).

Esquema alimentar para crianças não amamentadas: no 4 으 e no 5 으 meses devem seguir o esquema alimentar de recomendado para crianças amamentadas no 6ㅇ e no 7으 meses, respectivamente.

Amassar os alimentos com garfo.

Não liquidificar e não passar em peneira.

Os alimentos dever ter consistência de papa ou purês.

Evitar sopas e sucos.

Aos 6 meses: carne e legumes e/ou verduras $1 \mathrm{vez}$ ao dia.

A partir dos 7 meses: carne e legumes e/ou verduras 2 vezes ao dia.

Como sobremesa, fruta (sem adicionar açúcar).
Oferecer 3 refeições a partir dos 6 meses, sendo 1 de sal, e 4 a partir de 7 meses, sendo 2 de sal.
Começar com alimentos pastosos e semissólidos até chegar à consistência da família.

A partir dos 6 meses, oferecer alimentos pastosos.

A partir dos 8 meses, oferecer alimentos semissólidos e sólidos.

Frutas ricas em vitamina $A$ e hortaliças deveriam ser comidas diariamente.

Carne, aves, peixes ou ovo deveriam ser oferecidos sempre que possível.

(continua) 
Tabela 1 (continuação)

Atributos/
Componentes/
Marcadores
Densidade energética
Consumo de
produtos alimentícios
ultraprocessados

Evitar oferecer bebidas com baixo valor nutritivo, tais como café, chá, bebidas açucaradas e refrigerantes.

Segurança

Inocuidade microbiológica

Presença de aditivos alimentares

\begin{abstract}
Lavar as mãos do cuidador e da criança antes de preparar a comida e antes de comer.

Armazenar alimentos de forma segura e servir alimentos imediatamente após o preparo.

Usar utensílios limpos para preparar e servir a comida.

Usar copos e pratos limpos para alimentar as crianças.

Evitar o uso de mamadeiras, que são difíceis de manter limpas.
\end{abstract}

Evitar oferecer bebidas com baixo valor nutritivo, tais como café, chá, bebidas açucaradas e refrigerantes.
Passo 8: Evitar açúcar, café, enlatados, frituras, refrigerantes, balas, guloseimas, nos primeiros anos de vida. Usar sal com moderação.

Ministério da Saúde $(2002 * \star / 2010 * \star \star)$
SMSDC-RJ (2012 \#)

Adotada no estudo salgadinho e outras

Não é saudável a criança experimentar: balas, gelatina, geleia de mocotó, refrigerantes, guaraná natural, sucos artificiais, bebidas à base de soja, café, achocolatados, iogurtes industrializados, biscoitos recheados ou salgados, macarrão instantâneo, enlatados, embutidos, frituras, bebidas alcoólicas.

Passo 9: Cuidar da higiene no preparo e manuseio dos alimentos; garantir o seu armazenamento e conservação adequados.

\section{Atenção à higiene no preparo, manuseio e armazenamento dos alimentos.}

Evitar uso da mamadeira.

Não oferecer mel para crianças menores de 1 ano.

Passo 8: Evitar açúcar, café, enlatados, frituras, refrigerantes, balas, salgadinho e outras guloseimas, nos primeiros anos de vida. Usar sal com moderação.

Não é saudável a criança experimentar: balas, gelatina, geleia de mocotó, refrigerantes, guaraná natural, sucos artificiais, bebidas à base de soja, café, achocolatados, iogurtes industrializados, biscoitos recheados ou salgados, macarrão instantâneo, enlatados, embutidos, frituras, bebidas alcoólicas.
Lavar as mãos do cuidador e da criança antes de preparar a comida e antes de comer.

\section{Armazenar alimentos} de forma segura e servir alimentos imediatamente após o preparo.

Usar utensílios limpos para preparar e servir a comida.

Usar copos e pratos limpos para alimentar as crianças.

Evitar o uso de mamadeiras, que são difíceis de manter limpas.

Evitar açúcar, achocolatado, margarina, requeijão, café, enlatados, frituras, refrigerantes, mate, guaraná natural, balas, biscoitos recheados e salgados, sucos industrializados, gelatinas, sorvetes e picolés, bolos, tortas e outras guloseimas.

\footnotetext{
* World Health Organization 26;

** Secretaria de Atenção à Saúde, Ministério da Saúde 1;

*** Coordenação-Geral de Alimentação e Nutrição, Departamento de Atenção Básica, Secretaria de Atenção à Saúde, Ministério da Saúde 23.

\# Instituto de Nutrição Annes Dias; Instituto de Nutrição, Universidade do Estado do Rio de Janeiro; Instituto de Nutrição Josué de Castro,

Universidade Federal do Rio de Janeiro; Faculdade de Nutrição, Universidade Federal Fluminense; Escola de Nutrição, Universidade Federal do Estado do Rio de Janeiro 27.
} 
Tabela 2

Atributos e componentes da alimentação complementar, recomendações para sua concretização, indicadores para sua mensuração e perguntas utilizadas para sua construção. Rio de Janeiro, Brasil, 2013.

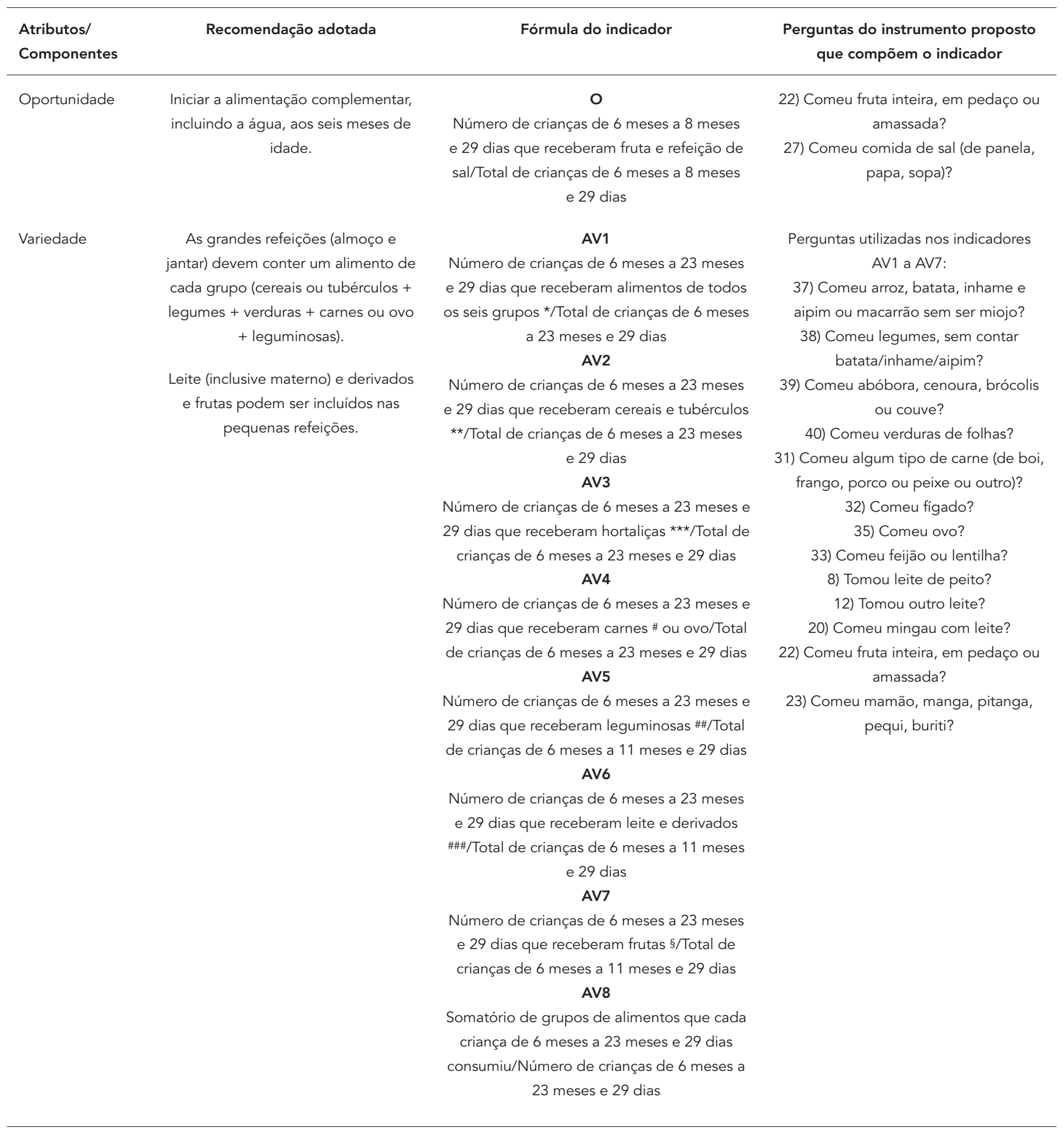

(continua) 
Tabela 2 (continuação)

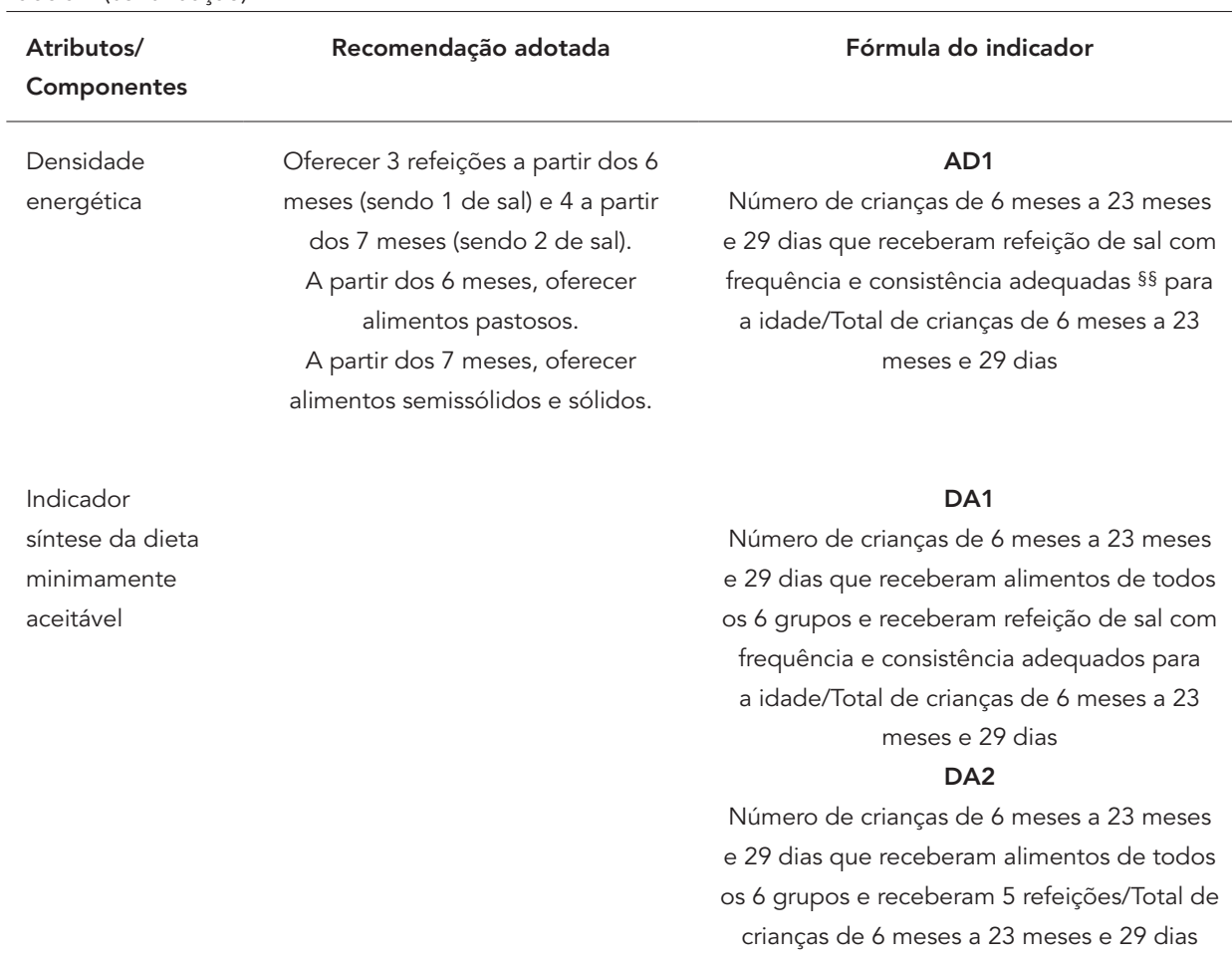

Oferta de alimentos fonte de nutrientes específicos

\section{Frutas ricas em vitamina $\mathrm{A}$ e hortaliças devem ser comidas diariamente.}

Carne, aves, peixes ou ovo devem ser oferecidos sempre que possível.
Consumo de produtos ultraprocessados
Evitar açúcar, achocolatado, margarina, requeijão, café, enlatados, frituras, refrigerantes, mate, guaraná natural, balas, biscoitos, salgadinhos, sucos industrializados, gelatinas, sorvetes e picolés, bolos, tortas e outras guloseimas.

\section{AN1}

Número de crianças de 6 meses a 23 meses e 29 dias que receberam alimentos ricos em ferro §§§/Número de crianças de 6 meses a 23 meses e 29 dias

\section{AN2}

Número de crianças de 6 meses a 23 meses e 29 dias que receberam alimentos ricos em vitamina $A$ †/Número de crianças de 6 meses a 23 meses e 29 dias

\section{AU1}

Proporção de crianças de 6 meses a 23 meses e 29 dias que consumiram cada um dos produtos ultraprocessados t†/Número de crianças de 6 meses a 23 meses e 29 dias AU2

Somatório dos produtos ultraprocessados que cada criança de 6 meses a 23 meses e 29 dias consumiu/Número de crianças de 6 meses a 23 meses e 29 dias
Perguntas do instrumento proposto que compõem o indicador

27) Comeu comida de sal (de panela, papa, sopa)?

28) Quantas vezes?

29) Essa comida foi oferecida: em pedaços/amassada/passada na peneira/liquidificada?

Perguntas utilizadas nos indicadores AV2 a AV7 e AD1.

Ferro, Carnes/ovo:

31) Comeu algum tipo de carne (de boi, frango, porco ou peixe ou outro)?

$$
\begin{gathered}
\text { 32) Comeu fígado? } \\
\text { 35) Comeu ovo? } \\
\text { Leguminosas: }
\end{gathered}
$$

33) Comeu feijão ou lentilha?

$$
\text { Vitamina A: }
$$

23) Comeu mamão, manga, pitanga,

$$
\text { pequi, buriti? }
$$

32) Comeu fígado?

39) Comeu abóbora, cenoura, brócolis ou couve?

14) Nesse leite tinha açúcar ou achocolatado?

16) Tomou suco industrializado ou em pó?

17) Tomou refrigerante?

41) Comeu salsicha, linguiça e/ou nugget?

42) Comeu macarrão instantâneo (tipo miojo)?

25) Comeu bala, pirulito ou outras guloseimas?

26) Comeu bolacha, biscoito ou salgadinho de pacote? 
Tabela 2 (continuação)

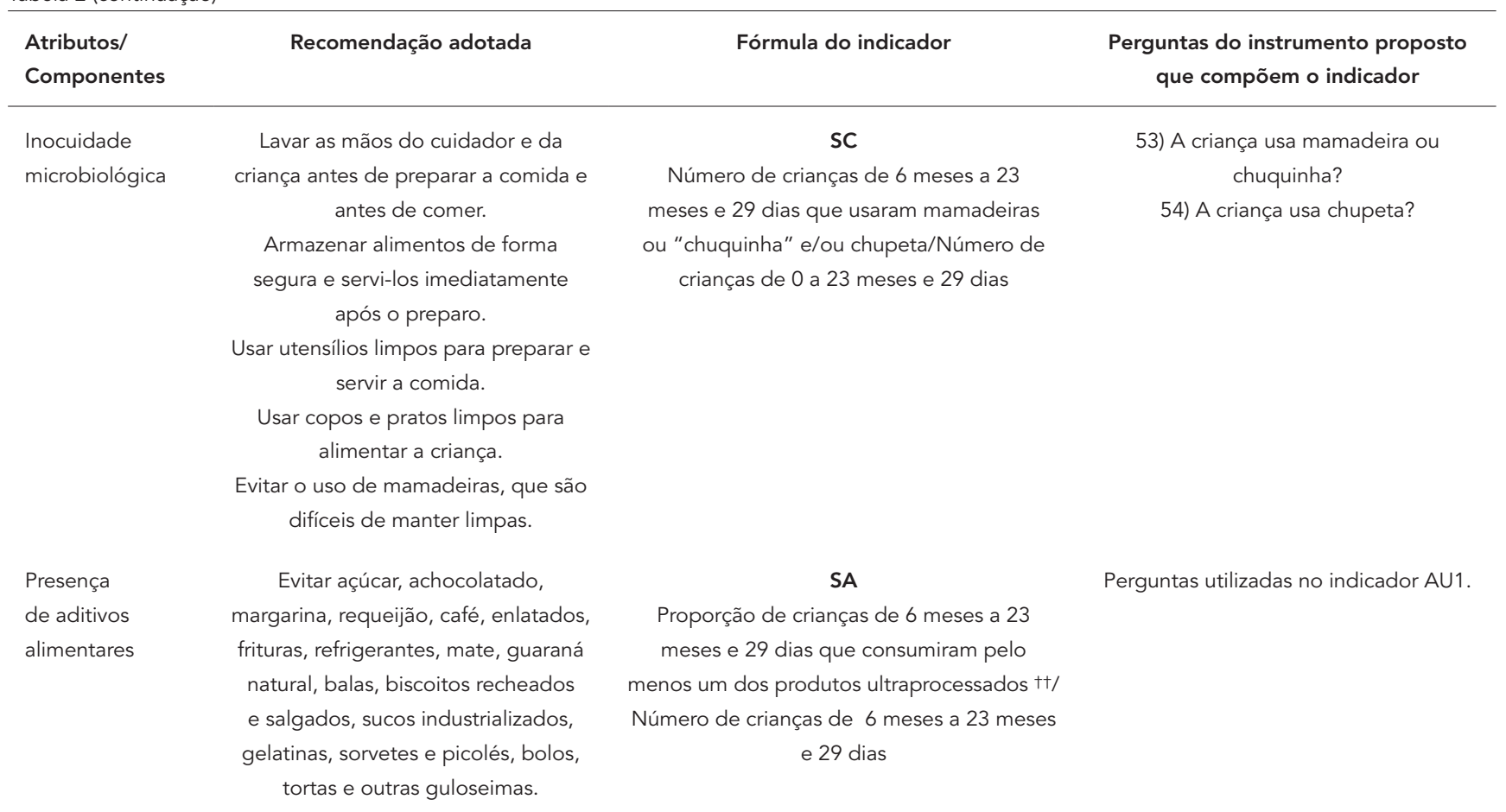

AD: Indicadores da Adequação - Densidade Energética; AN: Indicadores da Adequação - Nutrientes Específicos; AU: Indicadores da Adequação Ultraprocessados; AV: Indicadores da Adequação - Variedade; DA: Indicadores da Dieta (Minimamente) Aceitável; O: Indicador da Oportunidade;

SA: Indicador da Segurança - Aditivos; SC: Indicador da Segurança - Contaminação.

* Cereais e tubérculos, hortaliças, frutas, carnes ou ovo, leguminosas, leite (incluindo o materno) e derivados, frutas;

** Arroz, batata, inhame, aipim, macarrão;

*** Abóbora, cenoura, brócolis, couve, verduras de folhas;

\# Carne de boi, frango, porco, peixe, fígado, outro;

\#\# Feijão, lentilha;

\#\#\# Leite de peito, outro leite, mingau com leite;

$\S$ Fruta inteira, em pedaço ou amassada, mamão, manga, pitanga, pequi, buriti;

$\S \S$ Crianças de 6 meses a 7 meses e 29 dias: pelo menos uma refeição de sal com consistência sólida, semissólida ou pastosa; crianças de 8 meses a 11 meses e 29 dias: pelo menos duas refeições de sal com consistência sólida ou semissólida; crianças de 12 meses a 23 meses e 29 dias: pelo menos duas refeições de sal com consistência sólida ou semissólida;

$\S \S \S$ Carne (de boi, frango, porco ou peixe ou outro), fígado, ovo, feijão, lentilha;

† Mamão, manga, pitanga, pequi, buriti, fígado, abóbora, cenoura, brócolis, couve;

†† Achocolatado, suco industrializado ou em pó, refrigerante, salsicha, linguiça, nuggets, macarrão instantâneo, bala, pirulito, biscoito, salgadinho de pacote.

terceiro, foram também entrevistadas 13 mães, tendo sido abordados os seguintes alimentos ou grupos de alimentos: alimento sólido, semissólido e pastoso (novamente), suco industrializado ou em pó, comida de sal (novamente), legumes, verduras de folhas (novamente) e bolacha, biscoito ou salgadinho de pacote.

Com base nos resultados dos dois pré-testes, foram realizados alguns ajustes no questionário, chegando-se à versão final do instrumento de coleta de dados (apresentada adiante, na seção de resultados), que apresenta apenas questões fechadas, tendo "sim" ou "não" ou "não sei" como opções de resposta. Para algumas perguntas, quando a resposta da questão anterior for afirmativa, investiga-se o número de vezes que se consumiu tal alimento/preparação.

\section{Resultados}

\section{Indicadores}

Ao todo, são propostos 18 indicadores, organizados de acordo com a recomendação adotada para cada componente do modelo teórico proposto no presente estudo (Tabela 2). Para a maioria dos indicadores, a faixa etária proposta no indicador 
original pode ser estratificada, por exemplo, nas seguintes faixas: 6 meses a 11 meses e 29 dias, 12 meses a 17 meses e 29 dias, 18 meses a 23 meses e 29 dias. Todos os indicadores são expressos em proporções, com exceção dos indicadores AV8 e AU2, que são expressos na forma de médias. Cabe registrar, ainda, que todos os indicadores podem ser construídos para crianças amamentadas e não amamentadas.

\section{Pré-testes}

Os resultados dos pré-testes de entendimento estão sistematizados na Tabela 3. Alguns achados merecem ser destacados: para as mães entrevistadas, os termos "miúdos", "sólido", "semissólido" e "pastoso" foram de difícil compreensão; o termo "hambúrguer" foi compreendido de diferentes formas e os termos "mingau", "comida de sal", "verdura de folha", "achocolatado" e "adoçado" foram de fácil compreensão. Já com base no préteste de operacionalização, observou-se que o tempo médio de aplicação do instrumento como um todo foi de seis minutos.

\section{Versão final do instrumento para coleta de dados}

O questionário aqui proposto possui 36 questões sobre a alimentação da criança no dia anterior à investigação (Figura 2). Com base nelas, podem ser construídos os indicadores apresentados anteriormente. Com o intuito de subsidiar estudos futuros que venham a utilizar o questionário apresentado, além daquelas referentes à alimentação, mantiveram-se outras questões que têm feito parte do questionário aplicado nos inquéritos em dias de campanha de vacinação. Cumpre registrar que se buscou manter a estrutura das questões o mais próximo possível daquelas presentes no instrumento de coleta de dados utilizado na pesquisa realizada nas capitais brasileiras em 2008, de forma a permitir a construção de indicadores de amamentação e a comparação dos resultados de futuros estudos com os do último inquérito.

Importa esclarecer também que, além das perguntas necessárias à construção dos indicadores apresentados neste estudo, foram incluídas no questionário algumas perguntas que permitem a construção dos indicadores recomendados pela OMS não contemplados no elenco de indicadores aqui propostos, tendo em vista a discordância em relação à sua construção. As perguntas são: "Comeu algum alimento sólido, semissólido ou pastoso?/Quantas vezes?”. Procedeu-se dessa forma com o intuito de apresentar um instrumento que permita eventuais compa- rações de dados produzidos por ele com estudos realizados em outros países que adotem os indicadores e o questionário da OMS.

\section{Discussão}

Os produtos centrais deste estudo são um elenco de 18 indicadores sobre alimentação complementar e um questionário contendo 59 questões, sendo 36 sobre práticas alimentares de crianças menores de dois anos, que pode ser utilizado tanto em inquéritos em que se realizam entrevistas face a face quanto naqueles realizados por telefone ou, ainda, em atividades de monitoramento do consumo alimentar na rotina dos serviços de saúde.

A opção por um modelo teórico foi fundamental para o estudo, uma vez que norteou a escolha dos indicadores. Vale registrar que, ainda que o elenco de indicadores proposto abarque boa parte dos componentes, atributos e marcadores da alimentação complementar apresentados no modelo teórico, alguns deles não foram expressos em indicadores. No caso da adequação nutricional, por exemplo, não foi proposta uma forma de se medir a quantidade de cada preparação consumida para compor a análise da densidade energética, uma vez que isso implicaria o detalhamento do questionário, acarretando o aumento no tempo necessário para sua aplicação. Além disso, não foi proposta uma forma de se medir o uso de água própria para o consumo no preparo das refeições, relacionado ao atributo da segurança. Ainda com relação a esse atributo, o marcador higiene de utensílios foi reduzido ao uso de bicos (mamadeiras, "chuquinhas" e chupetas), o que, na verdade, mede a exposição da criança à utilização de um utensílio que pode ou não estar em condições inadequadas de higiene.

Comparando-se o questionário proposto com aquele utilizado na II Pesquisa Nacional Sobre Práticas Alimentares no Primeiro Ano de Vida, ocorrida em 2008, pode-se dizer que o instrumento aqui apresentado aborda de forma mais detalhada tanto o consumo dos grupos de alimentos e a consistência das refeições oferecidas quanto o consumo de produtos ultraprocessados.

No cotejamento dos indicadores aqui propostos com aqueles preconizados pela OMS podem ser identificadas algumas diferenças comentadas a seguir. Para o indicador de oportunidade, utilizou-se como marcador a presença de uma papa doce e comida de sal aos 6-8,9 meses, ao passo que a OMS propõe que esse indicador seja construído com base na pergunta referente a alimentos pastosos, semissólidos e sólidos. 
Tabela 3

Compreensão de mães de crianças menores de dois anos em relação a perguntas * sobre alimentação complementar. Rio de Janeiro, Brasil, 2012.

\section{Perguntas (mães abordadas)}

Quando perguntei "Tomou mingau?", no que você pensou? ( $n=5)$

Quando perguntei "Comeu comida de sal (de panela, papa, sopa)?", no que você pensou? $(n=18)$

Quando perguntei "Comeu algum tipo de carne de boi, frango, peixe, miúdos?", no que você pensou? $(n=11)$

Quando perguntei "Comeu alimento sólido, semissólido ou pastoso", no que você pensou? $(n=26)$

Poderia dar exemplos? $(n=13)$

Quando perguntei "Comeu fritura?", no que você pensou? $(n=13)$

Quando perguntei "Comeu legumes, sem contar batata/inhame/aipim?", no que você pensou? ( $n=13$ )

Quando perguntei "Comeu verdura de folha", no que você pensou? $(n=26)$

Quando perguntei "Comeu hambúrguer", no que você pensou? Industrializado ou caseiro? $(n=13)$

Quando perguntei "Nesse leite tinha achocolatado?", no que você pensou? $(n=13)$

\section{Respostas}

"Cremogema"; "Que fosse no prato. Como preparo? Fervo o leite e coloco cremogema. Ofereço no lanche"; "Ah! Mingau de aveia"; "Farinha láctea, mucilon" .

"Sopinha de legumes"; "Comida da gente, normal"; "Pensei em legumes"; "Comida de sal com batata, caldo de feijão, canja. A minha mãe que faz"; "Pensei na papinha que vou oferecer a ele em breve"; "Que ainda não é o momento. É comida que a gente prepara"; "Comida da gente comer, de adulto"; "Comida de casa: arroz e feijão"; "Arroz e feijão"; "Se ela comeu arroz, feijão etc."; "Carne, arroz, feijão"; "Na comida que ela só pode comer depois de seis meses"; "Comida pronta, comida de casa"; "Almoço e janta".

A maioria respondeu não ter entendido a pergunta.

"Carne picadinha?" ( $n=1)$.

"Legumes com caldo"; "Alimentação saudável"; "Comida: almoço e jantar"; "Comida ou mingau"; "Que seja pesado"; "Sopinha"; "Batido no liquidificador"; "No mamão que dei pra ele"; "Papa, mas só daqui a pouco"; "Sopa"; "Mingau"; "Não entendi a sua pergunta"; "Só sei o pastoso, que é batido. Os outros não sei"; "Não sei o que é. Não vem nada na minha cabeça"; "Sólido? Sei lá!"; "Biscoito, carne, arroz"; "Só quando tiver seis meses, aí pode dar sopa. Por enquanto ainda não"; "É comida - ela ainda não pode"; "Amassadinho, bem molinho"; "Pensei na consistência da alimentação dele".

Sólido: "proteína sem gordura", "arroz", "pedaço de maçã", "biscoito", "soja", "mingau", "algo mais sequinho", "beterraba", "feijão (caroço)", " inteiro (arroz e feijão)".

Semissólido: "comida seca", "leite desnatado, batido no liquidificador", "pedaço de maçã amassado", "arroz com feijão misturados", "banana", "papinha de fruta", "algo em pedaços", " tipo pastoso (inhame, por exemplo)", "meio molinho", "mingau mais ralo", "meio amassado".

Pastoso: "papa", "purê", " iogurte", "gelatina", "mingau", "algo mais molinho, como mamão", "papa batida no liquidificador", "mais fino (bater carne com feijão no liquidificador)", "sopa", "algo bem amassado".

"Tudo que é frito: batata frita, frango frito"; "Algo frito, por exemplo nuggets"; "Frango, carne frita"; "Batata frita, carne no óleo, salgadinho"; "Feito no óleo: bife, batata frita, salgadinho de festa"; "Frango no óleo, peixe frito"; "Salgadinho, hambúrguer, ovo frito"; "Coisas fritas no óleo: batata frita ou carne"; "Alimento frito: frango, peixe"; "Batata frita!".

"Cenoura"; "Que batata e inhame são os de início da alimentação"; "Outros tipos"; "Outros tipos de legumes"; "Nem pensei porque ele é muito pequeno"; "Cenoura, chuchu"; "Beterraba"; "Chuchu, cenoura, abobrinha"; "Nos legumes que fazem bem pra saúde"; "Chuchu, beterraba"; "Legumes (chuchu, abobrinha) que ele come normalmente".

"Alface"; "Couve"; "Brócolis"; "Agrião"; "Repolho"; "Coentro"; "Espinafre"; "Que ele não pode comer que engasga. Folha só brócolis, mas na sopa"; "Alface e espinafre"; "Vagem e agrião"; "Couve, alface, brócolis"; "Que pra criança precisa bater no liquidificador, porque se não engasga"; "Alface, couve"; "Verduras: alface, couve...".

"Só carne (frito); industrializado"; "Lanche; industrializado"; "Pão com carne; industrializado"; "Pão e carne; industrializado ou caseiro"; "Com pão, para o lanche; industrializado"; "Carne moída frita; industrializada"; "A carne ou o sanduíche, depende; caseiro"; "Só na carne; caseiro"; "Só a carne; industrializado"; "No sanduíche; industrializado"; "Carne moída prensada; industrializado"; "Sanduíche: pão e carne; industrializado".

"Nescau"; "Chocolate em pó"; "Tudo que vem do cacau: Nescau, Toddy etc.".

(continua) 
Tabela 3 (continuação)

\begin{tabular}{|c|c|}
\hline Perguntas (mães abordadas) & Respostas \\
\hline $\begin{array}{l}\text { Se fosse de morango ou outro sabor, você } \\
\text { chamaria de achocolatado? Como chamaria? } \\
(n=13)\end{array}$ & $\begin{array}{l}\text { "Se fosse de morango, daria nome Nesquik - não chamaria de achocolatado"; "Se fosse de morango, } \\
\text { também chamaria de achocolatado"; "Se fosse de morango, chamaria de achocolatado de outra cor"; } \\
\text { "Chamaria de... não sei!". }\end{array}$ \\
\hline $\begin{array}{l}\text { Quando perguntei "Recebeu alimento adoçado } \\
\text { com açúcar, mel, melado ou adoçante?", no } \\
\text { que você pensou? ( } \mathrm{n}=19 \text { ) }\end{array}$ & $\begin{array}{l}\text { "Que misturei na mamadeira"; "No líquido"; "Leite, vitamina, mingau"; "Leite, mingau, não sobre a } \\
\text { fruta"; "Mingau, suco... mais para líquidos"; "Suco. Não adoçaria fruta porque não precisa"; "O leite. } \\
\text { Não adoçaria fruta"; "Leite, mingau... mais para líquidos"; "No mingau, no Mucilon. Não adoçaria } \\
\text { sólido porque adoçar é mais para leite"; "No mingau - não é comum adoçar fruta"; "No leite, no } \\
\text { suco... a fruta já é doce"; "No leite e no mingau. Na fruta não - já tem o açúcar natural"; "Suco ou } \\
\text { leite. Sólido só se fosse fruta amassada". }\end{array}$ \\
\hline $\begin{array}{l}\text { Quando perguntei "Comeu bolacha, biscoito } \\
\text { ou salgadinho de pacote?", no que você } \\
\text { pensou? }\end{array}$ & $\begin{array}{l}\text { "Biscoito maisena"; "Nos tipos de biscoito, como maisena"; "Biscoito de chocolate"; "Biscoito } \\
\text { 'de vento'"; "Biscoito recheado. Salgadinho de pacote não sei"; "Biscoito de maisena, de água } \\
\text { e sal, amanteigado..."; "Nos tipos de biscoito cheios de química, que faz mal"; "Em besteiras - } \\
\text { nem pensar!"; "Biscoito Fandangos, biscoito recheado... porcarias"; "Biscoito maisena e biscoito } \\
\text { 'porcaritos'. Pensei se ele já comeu isso". }\end{array}$ \\
\hline $\begin{array}{l}\text { Quando perguntei "Tomou suco industrializado } \\
\text { ou em pó?", no que você pensou? (n = 19) }\end{array}$ & $\begin{array}{l}\text { "Suco de caixinha"; "Suco de garrafa"; "Suco de pacote ou de garrafa"; "De caixinha, Ades"; "Suco } \\
\text { que se compra pronto"; "Del Valle"; "Ki-suco"; "Tang"; "Ki-suco e pronto (de caixinha)"; "Aquele } \\
\text { suquinho em pó, de pacote"; "Suco que não se deve dar pra criança"; "Que ela não tem idade pra } \\
\text { isso"; "Suco Tang, suco de caju (da garrafinha), Ades de caixinha"; "Que isso ele não vai tomar isso tão } \\
\text { cedo porque é porcaria". }\end{array}$ \\
\hline $\begin{array}{l}\text { Quando perguntei "Comeu macarrão } \\
\text { instantâneo?", no que você pensou? }(n=6)\end{array}$ & $\begin{array}{l}\text { "Miojo"; "Miojo - todo mundo sabe"; "Que se perguntasse tipo miojo seria mais fácil de entender"; } \\
\text { "Esses aí que ficam pronto rápido". }\end{array}$ \\
\hline
\end{tabular}

* Perguntas que compunham o questionário aplicado em três pré-testes nos quais, em conjunto, foram abordadas 37 mães.

Optou-se por esse marcador por entender-se que é a introdução desse tipo de preparações no início do segundo semestre de vida que caracteriza a alimentação complementar oportuna e não a introdução de qualquer tipo de alimento com maior consistência (por exemplo, biscoitos), como considerado pela OMS. Além disso, os resultados dos pré-testes de entendimento realizados neste estudo indicaram que os termos sólido, semissólido e pastoso não são de fácil compreensão pelas mães, o que compromete a validade dessa pergunta.

Também houve diferença em relação à densidade energética: no presente estudo, adotouse como marcador de frequência das refeições a refeição de sal combinada com a consistência das preparações oferecidas, enquanto a OMS considera a oferta de qualquer alimento sólido, semissólido ou pastoso. Aqui, assumiu-se que se deve considerar o consumo de refeição de sal em consistência adequada à idade como marcador de densidade energética e não o consumo de qualquer alimento sólido (por exemplo, biscoito). Conforme comentado acima, aqui também vale o questionamento sobre a validade da pergunta utilizada pela OMS para construção desse indicador, dado que ela foi de difícil compreensão entre as mulheres entrevistadas.
Em relação à variedade, o indicador aqui proposto é composto por seis grupos (cereais e tubérculos; hortaliças; frutas; carnes ou ovo; leguminosas; leite e derivados - incluindo o materno) e considera que ela foi atingida se a criança consumir pelo menos um alimento de cada grupo. Já o indicador proposto pela OMS abrange sete grupos de alimentos (grãos, raízes e tubérculos; leguminosas e oleaginosas; produtos lácteos; carnes (vermelha, de peixe, frango, vísceras); ovos; frutas e hortaliças ricas em vitamina A (abóbora, cenoura, batata doce, manga e mamão papaia) e outras frutas e hortaliças, e considera que a variedade foi atingida quando pelo menos quatro desses grupos estão presentes na alimentação da criança. Além disso, no grupo de produtos lácteos, não considera o leite materno. Esses dois aspectos levam a implicações relevantes para o monitoramento da alimentação complementar. A primeira delas é que crianças com alimentação com variedade insuficiente podem ser classificadas como tendo uma alimentação variada (por exemplo, que consomem somente alimentos dos grupos de grãos, lácteos, carnes e ovos). A segunda é a de que crianças que são amamentadas e não consomem outros alimentos lácteos ficam em desvantagem em relação a outras que consomem esses produtos (estando amamentadas 
Incluir texto de abordagem introdutória adequado ao tipo de entrevista que estiver sendo realizada (face a face ou por telefone).

01-Data: 03-Município:

05-Data de nascimento desta crianç:

06-Sexo da criança: 1 ( ) Masculino $\overline{2(~}) \overline{\text { Feminino }}$

07-Qual a raça/cor da criança? 1 ( ) amarela 2( ) branca 3 ( ) parda 4 ( ) negra

02-Entrevistador:

04-UF:

A senhora pode me dizer quais alimentos esta criança tomou ou comeu desde ontem de manhã até hoje, sem contar com a primeira refeição da manhã? Eu vou falar o nome de cada alimento e a Sra. responde sim ou não.

08-Tomou leite de peito? 1 ( ) Sim 2( ) Não (passe para questão 10) 9 ( ) Não sabe (passe para questão 10)

09-Quantas vezes? vezes 9 ( ) Não sabe

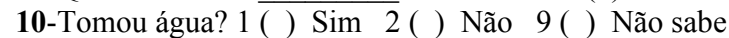

11-Tomou chá? 1 ( ) Sim 2( ) Não 9 ( ) Não sabe

12-Tomou outro leite? 1 ( ) Sim 2 ( ) Não (passe para questão 15) 9 ( ) Não sabe (passe para questão 15)

13-Quantas vezes a criança recebeu esse outro leite? ve_ vezes 9 ( ) Não sabe

14-Nesse leite tinha açúcar ou achocolatado? 1 ( ) Sim 2( ) Não 9 ( ) Não sabe

15-Tomou suco de fruta natural ou água de coco? 1 ( ) Sim 2 ( ) Não 9 ( ) Não sabe

16-Tomou suco industrializado ou em pó? 1 ( ) Sim 2( ) Não 9 ( ) Não sabe

17-Tomou refrigerante? 1 ( ) Sim 2 ( ) Não 9 ( ) Não sabe

18-Tomou café? 1 ( ) Sim 2 ( ) Não 9 ( ) Não sabe

19-Comeu algum alimento sólido semissólido ou pastoso? 1 ( ) Sim 2 ( ) Não 9 ( ) Não sabe

20-Comeu mingau com leite? 1 ( ) Sim 2( ) Não 9( ) Não sabe

21-Comeu outro tipo de mingau? 1 ( ) Sim 2 ( ) Não 9 ( ) Não sabe

22-Comeu fruta inteira, em pedaços ou amassada? 1 ( ) Sim 2 ( ) Não 9 ( ) Não sabe

23-Comeu mamão, manga, pitanga, pequi, buriti? 1 ( ) Sim 2 ( ) Não 9 ( ) Não sabe

24-Comeu alimento adoçado com açúcar, mel, melado, adoçante? 1 ( ) Sim 2 ( ) Não 9 ( ) Não sabe

25-Comeu bala, pirulito ou outras guloseimas? 1 ( ) Sim 2 ( ) Não 9 ( ) Não sabe

26-Comeu bolacha, biscoito ou salgadinho de pacote? 1 ( ) Sim 2 ( ) Não 9 ( ) Não sabe

27-Comeu comida de sal (de panela, papa, sopa)? 1 ( ) Sim 2 ( ) Não (passe para questão 28) 9 ( ) Não sabe (passe para questão 28)

28-Quantas vezes? 1 ( ) 1 vez 2( ) 2 vezes 3 ( ) 3 vezes ou mais 9 ( ) Não sabe

29-A comida oferecida foi: (Leia as alternativas. Se necessário assinale mais de uma alternativa.)

1 ( ) Igual à da família? 2 ( ) Preparada só para a criança? 3 ( ) Industrializada (de potinho)? 9 ( ) Não sabe

$\square$ Questão $29--$ (resposta codificada)

30-Essa comida foi oferecida como: (Leia as alternativas. Se necessário assinale mais de uma alternativa.)

1 ( ) Em pedaços? 2 ( ) Amassada? 3 ( ) Passada pela peneira? 4 ( ) Liquidificada? 9 ( ) Não sabe

$\square$ Questão 30 - - (resposta codificada)

31-Comeu algum tipo de carne (de boi, frango, porco ou peixe ou outro)? 1 ( ) Sim 2 ( ) Não 9 ( ) Não sabe

32-Comeu fígado? 1 ( ) Sim 2 ( ) Não 9 ( ) Não sabe

33-Comeu feijão ou lentilha? 1 ( ) Sim 2 ( ) Não (passe para questão 32) 9 ( ) Não sabe (passe para questão 32)

34-Como foi oferecido (feijão, lentilha ou ervilha): 1 ( ) Só caldo 2 ( ) Só caroço 3 ( ) Caldo e caroço 9( ) Não sabe

35-Comeu ovo? 1 ( ) Sim 2 ( ) Não (passe para questão 34) 9 ( ) Não sabe (passe para questão 34)

36-Como foi oferecido o ovo? 1 ( ) Só clara 2 ( ) Só gema 3 ( ) Clara e gema

37-Comeu arroz, batata, inhame, aipim ou macarrão sem ser miojo? 1 ( ) Sim 2 ( ) Não 9 ( ) Não sabe

38-Comeu legumes, sem contar batata/inhame/aipim? 1 ( ) Sim 2 ( ) Não 9 ( ) Não sabe

39-Comeu abóbora, cenoura, brócolis ou couve? 1 ( ) Sim 2( ) Não 9( ) Não sabe

40-Comeu verduras de folhas? 1 ( ) Sim 2( ) Não 9 ( ) Não sabe

41-Comeu salsicha, linguiça e/ou nuggets? 1 ( ) Sim 2( ) Não 9 ( ) Não sabe

42-Comeu macarrão instantâneo (tipo miojo)? 1 ( ) Sim 2 ( ) Não 9 ( ) Não sabe

43-Tomou ou comeu outros alimentos? 1 ( ) Sim 2( ) Não 9 ( ) Não sabe

(continua) 


\section{DADOS DO NASCIMENTO DA CRIANÇA}

44-Esta criança é o primeiro filho? 1 ( ) Sim 2 ( ) Não (considere apenas filhos nascidos vivos)

45-Em que município esta criança nasceu?

(anote o nome) 9( ) Não sabe

46-Em que hospital esta criança nasceu? (anote o nome)

1 ( ) Nasceu em casa 2( ) Casa de parto 3( ) HAC 4( ) Rede Cegonha 5( ) Outros 9( ) Não sabe

$\square$ Questão 46 - reposta codificada (Hospital Amigo da Criança ou Rede Cegonha)

47-Qual foi o tipo de parto? 1 ( ) Vaginal/Normal 2( ) Fórceps 3 ( ) Cesárea 9 ( ) Não sabe

48-A criança mamou no peito na primeira hora de vida, logo após o parto? 1 ( ) Sim 2( ) Não 9 ( ) Não sabe

49-Qual o peso desta criança ao nascer?___ gramas

50-Onde costumam levar a criança para as consultas de rotina? (Assinale apenas uma alternativa)

1 ( ) Serviço particular ou convênio Anote o nome:

Rede Pública:

99 ( ) Não sabe

$\square$ Questão 50 - se Rede Pública especificar: 2( ) UBS 3( ) PACS/ESF 4 ( ) Outros

51-A criança frequenta creche? 1 ( ) Sim 2( ) Não 9 ( ) Não sabe

52-Qual período? 1 ( ) Integral 2 ( ) Meio período (manhã ou tarde)

53-A criança usa mamadeira ou chuquinha? 1( ) Sim 2( ) Não 9( ) Não sabe

54-A criança usa chupeta? 1 ( ) Sim 2( ) Não 9( ) Não sabe

55-Qual é a idade da Sra.?

DADOS DA MÃE

56-A Sra. sabe ler e escrever? 1 ( ) Sim 2 ( ) Não

57-Qual a última série que cursou com aprovação? (assinale abaixo) 58-E grau? (assinale abaixo)
$0($ ) $1($ ) 2() 3() 4() 5() 6() 7() 8()
$1($ ) $2($ ) 3()
0 ( ) Sem escolaridade 1( ) Ensino Fundamental
2 ( ) Ensino Médio
$\square$ Questão 57
1 ( ) Incompleto
2 ( ) Completo
3 ( ) Superior
$\square$ Questão 58

59-Sobre o trabalho, neste momento a Sra.: (leia as alternativas e assinale apenas uma)

(resposta codificada)

1 ( ) Está trabalhando fora 2 ( ) Não está trabalhando fora 3 ( ) Está sob Licença-Maternidade

ou não) no tocante a esse grupo de alimentos, o que é uma distorção. Por isso, a OMS recomenda que os dados sejam analisados separando-se crianças amamentadas e não amamentadas, o que complexifica a interpretação dos achados. A terceira é que, da forma como está construído, esse indicador é influenciado pela prevalência da amamentação, o que dificulta sua comparação em realidades cuja prevalência desse evento é distinta. A segunda e a terceira implicações antes citadas são reconhecidas pela própria OMS 12 .

Neste estudo, foram priorizados como nutrientes específicos o ferro e a vitamina A, visto que são marcadores do crescimento e desenvolvimento infantil e a carência desses micronutrientes na população infantil é, reconhecidamente, um problema de saúde pública 1 . Em relação à investigação do consumo de alimentos ricos em ferro, diferentemente da proposta da OMS, para o cálculo do indicador do estudo não são levados em conta alimentos fortificados. No caso da vitamina A, propôs-se um indicador específico para esse micronutriente, que foi composto por frutas e hortaliças que são fontes desse micronutriente ou de seus precursores e, também, pelo fígado. Já na proposta da OMS, ele é considerado somente na composição do indicador de variedade. Além do indicador referente ao consumo de alimentos ricos em vitamina $\mathrm{A}$, os indicadores referentes ao consumo de produtos ultraprocessados e de aditivos alimentares são exclusivos do estudo, não sendo possível a comparação, pois não estão previstos no elenco de indicadores da OMS.

Por fim, vale ressaltar que são fundamentais estudos complementares que produzam evidências sobre as características psicométricas, a confiabilidade e a validade do instrumento em diferentes contextos 29 .

\section{Conclusão}

O presente trabalho apresentou, de forma pioneira, um elenco de indicadores de alimentação complementar para crianças menores de dois anos baseado em um modelo teórico sobre seus componentes e na sistematização de recomendações nacionais e internacionais sobre o tema. 
Propôs, ainda, um questionário que permite a construção desses indicadores e que é aplicável em contextos que demandem um tempo curto para coleta de dados. São necessárias novas pesquisas para a validação do questionário sugerido.

\section{Resumen}

El objetivo fue presentar indicadores y un instrumento de monitoreo para la alimentación complementaria entre niños menores de dos años en Brasil, describiendo el proceso de formulación. A partir de un modelo teórico de atributos, componentes y marcadores de alimentación complementaria, se sistematizaron las recomendaciones dietéticas sobre los conceptos clave del modelo. Estas recomendaciones se transformaron en indicadores. Se confeccionó un cuestionario, basado en las variables de los indicadores. Se realizaron dos talleres con expertos en alimentación complementaria para el debate sobre los indicadores y el instrumento y cuatro pruebas previas con la población de interés. El estudio presenta 18 indicadores respecto a oportunidad, adecuación nutricional y seguridad de la alimentación complementaria, y un cuestionario que permite la construcción de los indicadores propuestos. Puede ser aplicado en investigaciones científicas con entrevistas cara a cara, por teléfono o en actividades de monitoreo de la ingesta de alimentos en los servicios de salud. Son necesarias más investigaciones para validar el cuestionario.

Alimentación Suplementaria; Nutrición del Lactante; Ingesta Diaria Recomendada

\section{Colaboradores}

J. M. Oliveira e I. R. R. Castro participaram do delineamento, concepção e execução da pesquisa, da elaboração do texto e da revisão final. G. B. Silva participou da concepção e de etapas de execução da pesquisa e da elaboração do texto. S. I. Venancio e S. R. D. M. Saldiva participaram de etapas da execução da pesquisa e da elaboração do texto e da revisão final.

\section{Agradecimentos}

À FAPERJ pelo apoio financeiro (processo: E26/111. 434/2013). 


\section{Referências}

1. Secretaria de Atenção à Saúde, Ministério da Saúde. Guia alimentar para crianças menores de dois anos. Brasília: Ministério da Saúde; 2002. (Série A Normas e Manuais Técnicos, 107).

2. Portal Brasil. Alimentação adequada pode reduzir mortes de crianças, segundo Ministério da Saúde. http://www.brasil.gov.br/noticias/arqui vos/2012/04/30/alimentacao-adequada-podereduzir-mortes-de-criancas-segundo-ministerioda-saude (acessado em 01/Mai/2012).

3. Bortolini GA, Gubert MB, Santos LMP. Consumo alimentar entre crianças brasileiras com idade de 6 a 50 meses. Cad Saúde Pública 2012; 28:1759-71.

4. Coordenação-Geral de Alimentação e Nutrição, Departamento de Atenção Básica, Secretaria de Atenção à Saúde, Ministério da Saúde. Uso dos formulários e registro das informações no novo Sistema informatizado da Vigilância Alimentar e Nutricional - SISVAN WEB. http://nutricao.saude. gov.br/sisvan.php (acessado em 26/Nov/2012)

5. Centro Brasileiro de Análise e Planejamento; Ministério da Saúde. Pesquisa Nacional de Demografia e Saúde da Criança e da Mulher - PNDS 2006: dimensões do processo reprodutivo e da saúde da criança. Brasília: Ministério da Saúde; 2009. (Série G. Estatística e Informação em Saúde).

6. Venancio SI, Escuder MM, Saldiva SR, Giugliani ER. Breastfeeding practice in the Brazilian capital cities and the Federal District: current status and advances. J Pediatr (Rio J.) 2010; 86:317-24.

7. Carvalhaes MABL, Parada CMGL, Manoel CM, Venâncio SI. Diagnóstico da situação do aleitamento materno em área urbana do Sudeste do Brasil: utilização de metodologia simplificada. Rev Saúde Pública 1998; 32:430-6.

8. Departamento de Ações Programáticas e Estratégicas, Secretaria de Atenção à Saúde, Ministério da Saúde. II Pesquisa de Prevalência de Aleitamento Materno nas Capitais Brasileiras e Distrito Federal. Brasília: Editora MS; 2009. (Série C. Projetos, Programas e Relatórios).

9. Sena MCF, Silva EF, Pereira MG. Prevalência do aleitamento materno nas capitais brasileiras. Rev Assoc Méd Bras 2007; 53:520-4.

10. Division of Child Health and Development, World Health Organization. Indicators for assessing breastfeeding practices. Geneva: World Health Organization; 1991.

11. World Health Organization. Complementary feeding of young children in developing countries: a review of current scientific knowledge. Geneva: World Health Organization; 1998.

12. Department of Child and Adolescent Health and Development, World Health Organization. Indicators for assessing infant and young child feeding practices: conclusions of a consensus meeting held 6-8 November 2007 in Washington D.C., USA. Part 1: definitions. Geneva: World Health Organization; 2008.
13. World Health Organization. Indicators for assessing infant and young child feeding practices. Part 2: measurement. Geneva: World Health Organization; 2010

14. World Health Organization. Indicators for assessing infant and young child feeding practices. Part 3: country profiles. Geneva: World Health Organization; 2010.

15. Monteiro CA, Levy RB, Claro RM, Castro IRR, Cannon G. A new classification of foods based on the extent and purpose of their processing. Cad Saúde Pública 2010; 26:2039-49.

16. Reichenheim ME, Moraes CL. Desenvolvimento de instrumentos de aferição epidemiológicos. In: Kac G, Sichieri R, Gigante DP, organizadores. Epidemiologia nutricional. Rio de Janeiro: Editora Fiocruz/Atheneu; 2007. p. 227-42.

17. Coordenação-Geral de Alimentação e Nutrição, Departamento de Atenção Básica, Secretaria de Atenção à Saúde, Ministério da Saúde. Estratégia nacional para alimentação complementar saudável. Caderno do tutor. Brasília: Ministério da Saúde; 2010.

18. Caetano MC, Ortiz TTO, Silva SGL, Souza FIS, Sarni ROS. Complementary feeding: inappropriate practices in infants. J Pediatr (Rio J.) 2010; 86: 196-201.

19. Saldiva SR, Escuder MM, Modini L, Levy RB, Venancio SI. Feeding habits of children aged 6 to 12 months and associated maternal factors. J Pediatr (Rio J.) 2007; 83:53-8.

20. Simon VGN, Souza JMP, Souza SB. Introdução de alimentos complementares e sua relação com variáveis demográficas e socioeconômicas, em crianças no primeiro ano de vida, nascidas em Hospital Universitário no município de São Paulo. Rev Bras Epidemiol 2003; 6:29-38.

21. Koletzko B, Dokoupil K, Reitmayr S, Weimert-Harendza B, Keller E. Dietary fat intakes in infants and primary school children in Germany. Am J Clin Nutr 2000; 72:1392-8.

22. Monteiro CA. The big issue is ultra-processing. World Nutrition 2010; 1:237-69.

23. Coordenação-Geral de Alimentação e Nutrição, Departamento de Atenção Básica, Secretaria de Atenção à Saúde, Ministério da Saúde. Dez passos para uma alimentação saudável: guia alimentar para menores de dois anos - um guia para o profissional da saúde na atenção básica. Brasília: Ministério da Saúde; 2010. (Série A. Normas e Manuais Técnicos).

24. Polônio MLT, Peres F. Consumo de aditivos alimentares e efeitos à saúde: desafios para a saúde pública brasileira. Cad Saúde Pública 2009; 25:1653-66

25. Schumann SPA, Polônio MLT, Gonçalves ECBA Avaliação do consumo de corantes artificiais por lactentes, pré-escolares e escolares. Ciênc Tecnol Aliment 2008; 28:534-9. 
26. World Health Organization. Guiding principles for complementary feeding of the breastfed child. Geneva: World Health Organization; 2003.

27. Instituto de Nutrição Annes Dias; Instituto de Nutrição, Universidade do Estado do Rio de Janeiro; Instituto de Nutrição Josué de Castro, Universidade Federal do Rio de Janeiro; Faculdade de Nutrição, Universidade Federal Fluminense; Escola de Nutrição, Universidade Federal do Estado do Rio de Janeiro. O que você precisa saber sobre a alimentação saudável para criança menor de 2 anos [folder]. Rio de Janeiro: Paralaxe Design; 2012.
28. Reichenheim ME, Moraes CL. Buscando a qualidade das informações em pesquisas epidemiológicas. In: Minayo MCS, Deslandes SF, organizadores. Caminhos do pensamento: epistemologia e método. Rio de janeiro: Editora Fiocruz; 2002. p. 227-54.

29. Streiner DL, Norman GR. Health measurement scales. a practical guide to their development and use. $4^{\text {th }}$ Ed. New York: Oxford University Press; 2008.

Recebido em 11/Dez/2013

Versão final reapresentada em 07/Ago/2014

Aprovado em 29/Ago/2014 